\title{
Orienting Engineering Ethics in terms of China: Curricula Shortcomings and Case Studies on China
}

\author{
Dr. Rockwell Franklin Clancy III, The University of Michigan-Shanghai Jiao Tong Joint Institute, Shanghai \\ Jiao Tong University
}

Rockwell F. Clancy is a lecturer at the University of Michigan-Shanghai Jiao Tong Joint Institute, Shanghai Jiao Tong University. His research and teaching interests include applied ethics, political philosophy, and science, technology, and society studies. Rockwell completed his PhD at Purdue University, West Lafayette, MA at the Katholieke Universiteit, Leuven, Belgium, and BA at Fordham University, New York.

\section{Miss Guangyu Zhang \\ Dr. Rockwell Franklin Clancy III, The University of Michigan-Shanghai Jiao Tong Joint Institute, Shanghai Jiao Tong University}

Rockwell F. Clancy is a lecturer at the University of Michigan-Shanghai Jiao Tong Joint Institute, Shanghai Jiao Tong University. His research and teaching interests include applied ethics, political philosophy, and science, technology, and society studies. Rockwell completed his PhD at Purdue University, West Lafayette, MA at the Katholieke Universiteit, Leuven, Belgium, and BA at Fordham University, New York.

Dr. Rockwell Franklin Clancy III, The University of Michigan-Shanghai Jiao Tong Joint Institute, Shanghai Jiao Tong University

Rockwell F. Clancy is a lecturer at the University of Michigan-Shanghai Jiao Tong Joint Institute, Shanghai Jiao Tong University. His research and teaching interests include applied ethics, political philosophy, and science, technology, and society studies. Rockwell completed his PhD at Purdue University, West Lafayette, MA at the Katholieke Universiteit, Leuven, Belgium, and BA at Fordham University, New York. 
Orienting Engineering Ethics in terms of China:

Curricula Shortcomings and Case Studies on China 


\section{Introduction}

This paper discusses a project in which we are currently engaged entitled "Orienting Engineering Ethics in terms of China and Chinese Values: Its Significance Based on Three Case Studies." This research has a two-fold aim: 1 to identify and rectify shortcomings in curricula addressing the ethical, social, and political dimensions of engineering in international environments, as well as misunderstandings in international engineering environments that result from these shortcomings; 2. to identify and rectify deficiencies within engineering curricula offered in China, as well as safety concerns that result from these deficiencies.

As this research is ongoing, here we simply share our findings thus far: the nature of shortcomings within current curricula and the way we seek to rectify these deficiencies by researching large-scale engineering projects in China and writing case studies to be used in courses dealing with the ethical, social, and political dimensions of engineering. These case studies address the decision to build the Three Gorges dam, the construction of the West-East pipeline, and coal mining and energy in China. We focus on differences between China and other countries rather than China and any other specific country. Although our project focuses on China specifically, these issues in China are relevant in addressing global engineering challenges, improving cross-cultural understanding and strengthening international collaborations as a result.

\section{Shortcomings (overview)}

First, this research identifies shortcomings in current curricula that address the ethical, social, and political dimensions of engineering in international environments, as well as misunderstandings in international engineering environments that result from these shortcomings. Second, our project is motivated by deficiencies within engineering curricula offered in China, as well as safety concerns that result from these deficiencies. As these motivations spring from the nature of current education, we discuss the nature of these curricula and their consequences.

\section{Shortcomings related to international curricula and cross-cultural understanding}

Texts for courses on engineering ethics, for example, are generally based on Western perspectives, where the theoretical framework used to address these dimensions are deontological and utilitarian in nature, and engineering is conceived in terms of the Western notion of professionalism. Issues that arise in international contexts are then treated secondarily, generally in the form of additional chapters on differing laws and business practices. ${ }^{1}$

Although we take the perspective that the principles of engineering ethics should be understood as cross-cultural, socially specific values and circumstances obviously contribute to international engineering. ${ }^{2,3}$ Given that engineering increasingly takes place in international and cross-cultural contexts, more space should be given in courses to the way social and political dimensions of engineering in international environments shape ethical concerns. 
Many foreigners working as engineers in Shanghai, for example, have expressed alarm and voiced concerns to me regarding differences in professional expectations and work environments from where they worked previously. To better prepare students to work in increasingly globalized environments, students can be made better aware of these differences and the roles they play in shaping international engineering environments through case studies.

\section{Shortcomings related to Chinese curricula and public safety}

In the last thirty years, China has developed more and more quickly than any society in human history. Recently, however, government policies have shifted from a primary concern with break-neck development to one where public safety is of increasing concern. ${ }^{4}$ Insofar as engineering is involved in all facets of modern life, here engineers play a significant role: to insure public safety, it is important that engineers in China engage in ethical practices.

At present, courses that deal with the ethical, social, and political dimensions of engineering are not a central feature of engineering curricula throughout China. Notable exceptions include the University of Michigan-Shanghai Jiao Tong Joint Institute, which requires that upperclassman complete a course called "Professional Ethics." Southwest Jiao Tong University in Chengdu requires a similar course. ${ }^{5}$ The University of Science and Technology Beijing was the first to establish this course in $1999,{ }^{6}$ and the Dalian University of Technology offers such courses, ${ }^{7}$ although they are not compulsory.

Given that current curricula dealing with the ethical, social, and political dimensions of engineering are generally based on Western perspectives, simply importing such curricula would be inappropriate. In my experience, Chinese students have a harder time understanding and are more resistant to the notion of "professional autonomy" than their US counterparts, and there are reasons to doubt this notion should be emphasized to the extent that it is in courses offered in the Western world. ${ }^{8}$

Failing to understand the central concepts and principles in courses dealing with the ethical and social implications of engineering written from and for a Western perspective, Chinese students fail to appreciate the responsibilities engineers have for insuring public safety. As engineering is involved in all facets of China's development, it is important that Chinese engineers be made aware of their responsibilities for public safety and engage in practices that foster this safety. ${ }^{9}$

\section{Case studies (overview)}

The anticipated outcomes of our project are two-fold: in the first place, to improve curricula that address the ethical, social, and political dimensions of engineering in international contexts and, therefore, improve cross-cultural understanding in international engineering environments; in the second place, to improve engineering curricula offered in China and, as a result, to contribute to public safety in China. We discuss the specific ways our research would contribute to innovation regarding the content of this education.

\section{Case studies and their relation to international curricula and cross-cultural understanding}


Although the research for our case studies focuses on China specifically, the issues we address in China are relevant to global engineering challenges. In the first place, our project addresses differences in perspectives that result from differing cultural assumptions. In so doing, we hope to enhance the quality of international collaborations through better cross-cultural understanding.

From an ethical perspective, for example, deontological frameworks are largely foreign to traditional Chinese systems of thought such as Confucianism. ${ }^{10}$ Here emphasis would be placed on the maintenance of social harmony. ${ }^{11}$ Assuming ethical commitments are based in large part on cultural values, given the significant cultural differences between China and other countries, different ethical commitments guide engineering projects in China. To prepare students to participate in increasingly globalized engineering environments, our case studies highlight the nature and importance of these different cultural and ethical perspectives, assuaging confusions and misunderstandings that result from ignorance of these differences.

Additionally, large-scale engineering projects undertaken in contemporary China have broader social and political implications and consequences than they might in, for example, present-day developed countries such as the United States and France. Projects such as the Three Gorges Dam, West-East pipeline, and the high-speed railway have been conceived as either points of national pride or humiliation, rather than as simply responses to energy, resource, and transportation needs. ${ }^{12,13,14}$ Conceived in terms of public works projects, these endeavors have the potential to either increase or decrease the livelihood of Chinese people in significant ways, as well as either building trust in the government or undermining its legitimacy. ${ }^{15,16}$

As responses to scarce resource needs, large-scale engineering projects shape China's foreign policy with both its neighbors and the rest of the world. As China continues its development, internal issues such as these will continue to shape its foreign policies, which have the potential to seriously affect the rest of the world. ${ }^{17}$ Although motivated by engineering concerns, issues such as these have far-reaching implications and consequences, touching on broader issues, for example, energy security and international diplomacy. ${ }^{18}$

To prepare students to work in increasingly globalized engineering environments, it is important that they be made aware of the abovementioned issues, taking cognizance of the social and political dimensions of engineering in international contexts. By identifying and discussing issues that arise in case studies on China, students will have a better understanding of and appreciation for the way circumstances and values foreign to their own shape engineering environments. This exercise would help to foster better understanding - insuring realistic expectations regarding the nature of international and cross-cultural environments - enhancing the quality of international collaborations through better cross-cultural understanding.

\section{Case studies and their relation to Chinese curricula and public safety}

Within China, we hope our research and case studies will help to foster the development of courses dealing with the ethical, social, and political dimensions of engineering, as well as alleviating concerns regarding public safety that result from deficiencies in current engineering curricula. 
In the first place, our case studies will result in the availability of Chinese-specific resources to be used in courses dealing with the ethical, social, and political dimensions of engineering. We hope the availability of such resources will facilitate the introduction of courses such as these into engineering curricula throughout China. As our project highlights the ways socially specific values and circumstances influence the nature of engineering in China, this focus will assuage difficulties Chinese students find in understanding materials developed from and for a Western perspective. Our research and case studies place greater emphasis on, for example, the nature of the communal good and shared responsibility in engineering contexts, as well as China's place as a developing country, where tradeoffs between rapid development and environmental wellbeing should occupy an important place. ${ }^{19}$

Additionally, as we show how national issues within China have global import, Chinese students will be better prepared to work in global engineering environments. By identifying and discussing issues that arise in case studies based on China, students would have an understanding of and appreciation for concepts and principles concerning the ethical and social implications of engineering, more fully appreciating and acting in a manner that insures public safety.

\section{Conclusion}

Although our research focuses on China specifically, the issues on which we focus in relation to China are globally relevant. We explained the findings of our research thus far: deficiencies in current curricula both internationally and within China, as well as the consequences of theses deficiencies. We hope our research and case studies will improve engineering curricula and, thereby, foster greater understanding in international engineering environments, as well as assuage concerns regarding public safety in China.

\section{References}

${ }^{1}$ Luegenbiehl, H. 2007, “Teaching Engineering Ethics across National Borders,” Journal of Engineering Education Research (South Korea), Vol. 10, No. 2, June, 106-17.

${ }^{2}$ Luegenbiehl, H. 2007, “Teaching Engineering Ethics across National Borders," Journal of Engineering Education Research (South Korea), Vol. 10, No. 2, June, 106-17.

${ }^{3}$ Harris, C., Pritchard, M, and Rabin, M. 2004, Engineering Ethics: Concepts and Cases, Belmont: Wadsworth Publishing.

${ }^{4}$ Ma D. and Adams W. 2013, In Line Behind a Billion People: How Scarcity Will Define China's Ascent in the Next Decade, NJ: FT Press.

${ }^{5}$ Xiao, P. 2006, "Ke Cheng Jie Shao: Gong Cheng Lun Li Xue" ("Introduction to the Course: Engineering Ethics"), Guo Jia Jing Pin Ke Cheng Zi Yuan Wang, Gong Cheng Lun Li Xue (The Net of Resources of High-Quality Courses of China), February 12, 2014 http://course.jingpinke.com/details/introduction?uuid=8a833999-221c4794-01221c479508-030f\&courseID=S0601077\&column=brief

${ }^{6}$ Xiao, P. 2006, "Ke Cheng Jie Shao: Gong Cheng Lun Li Xue” (“Introduction to the Course: Engineering Ethics"), Guo Jia Jing Pin Ke Cheng Zi Yuan Wang, Gong Cheng Lun Li Xue (The Net of Resources of High-Quality Courses of China), February 12, 2014 http://course.jingpinke.com/details/introduction?uuid=8a833999-221c4794-01221c479508-030f\&courseID=S0601077\&column=brief

7 “Ke Xue Ji Shu Yi Gong Cheng Lun Li Jiao Xue Da Gang,” 2013 (“Course Information for Engineering Ethics, Science, and Technology”), Teaching Affairs Division of Dalian University of Technology, November 15 
http://teach.dlut.edu.cn/tsjyzx/tsk/1/\%E7\%A7\%91\%E6\%8A\%80\%E8\%BF\%9B\%E6\%AD $\%$ A5\%E7\%B1\%BB/131.doc.

${ }^{8}$ Luegenbiehl, H. 2004, "Ethical Autonomy and Engineering in a Cross-Cultural Context," Techné: Research in Philosophy and Technology, Vol. 8, No. 1.

${ }^{9}$ Cao, N. 2004, "Dui Zhong Guo Gao Xiao Gong Cheng Lun Li Jiao Yu De Si Kao," ("Reflection on the Education of Engineering Ethics in China"), Gao Deng Jiao Yu Gong Cheng Yan Jiu (Advanced Engineering Education Research), 5. Wang, Q. 2009, “Gong Kai Ke: Ke Xue Ji Shu Yu Gong Cheng Lun Li” ("Public Course: Science, Technology, and Engineering Ethics"), Da Lian Li Gong Da Xue, (Dalian Technology University), http://www.icourses.cn/viewVCourse.action?courseCode=10141V003

${ }^{10}$ Hall, D. 1987, Thinking Through Confucius, Albany: State University of New York Press.

${ }^{11}$ Hwang, K. 1999, "Filial Piety and Loyalty: Two Types of Social Identification in Confucianism," Asian Journal of Social Psychology 2: 163-183.

${ }^{12}$ Heggelund, G. 2004 (ed.), Environment and Resettlement Politics in China: The Three Gorges Project, England: Ashgate.

${ }^{13}$ Yu, M. 2009, Ba Qian Li Lu Yu he Yue: Xing Zou Zai Xi Qi Dong Shu de Da Di Shang, (The Cloud and Months: Walking on the Ground of the West-East Pipeline), Chongqing: Chongqing Publishing Press.

14 "Andrew Browne talks about the fallout of China's deadly high-speed rail crash with Kelsey Hubbard" 2011 , Wall Street Journal Online, July 29, February 12, 2014 http://live.wsj.com/video/china-high-speed-rail-crash-sparksoutrage/099E9066-AE8A-4A6A-A813-0D1A67B3139E.html\#!099E9066-AE8A-4A6A-A813-0D1A67B3139E.

${ }^{15}$ Heggelund, G. 2004 (ed.), Environment and Resettlement Politics in China: The Three Gorges Project, England: Ashgate.

${ }^{16}$ Tian, H., et al. 2009, “Zhong Da Gong Cheng Jian She Qu Sheng Tai Huan Jing Guan Li de Gong Zhong Can Yu: Yi Xi Qi Dong Shu Gong Cheng Shan Xi Jing Bian Zhi Shanghai Duan Wei Li," ("Public Awareness regarding Environmental Management of Large-Scale Projects: A Case Study of the West-to-East Pipeline Project between Jinlin, Shanxi, and Shanghai”), Acta Ecologica Sinica 29.1.

${ }^{17}$ Hukil, R. 2013, "India, China, and Bangladesh: The Contentious Politics of the Brahmaputra River," Institute of Peace and Conflict Studies, March 9, http://www.ipcs.org/article/india/india-china-and-bangladesh-the-contentiouspolitics-of-the-brahmaputra-3840.html.

18 “Q\&A: China-Japan island row," 2013, BBC News: Asia, November 27 http://www.bbc.co.uk/news/world-asiapacific-11341139.

${ }^{19}$ Ma D. and Adams W. 2013, In Line Behind a Billion People: How Scarcity Will Define China's Ascent in the Next Decade, NJ: FT Press. 